University of Nebraska - Lincoln

DigitalCommons@University of Nebraska - Lincoln

USDA Forest Service / UNL Faculty Publications U.S. Department of Agriculture: Forest Service -National Agroforestry Center

2009

\title{
Remote sensing for prediction of 1-year post-fire ecosystem condition
}

Leigh B. Lentile

University of Idaho, Iblentil@sewanee.edu

Alistair M.S. Smith

University of Idaho, alistair@uidaho.edu

Andrew T. Hudak

Rocky Mountain Research Station, ahudak@fs.fed.us

Penelope Morgan

University of Idaho, pmorgan@uidaho.edu

Michael J. Bobbitt

University of Idaho, mbobbitt@uidaho.edu

See next page for additional authors

Follow this and additional works at: https://digitalcommons.unl.edu/usdafsfacpub

Lentile, Leigh B.; Smith, Alistair M.S.; Hudak, Andrew T.; Morgan, Penelope; Bobbitt, Michael J.; Lewis, Sarah A.; and Robichaud, Pete, "Remote sensing for prediction of 1-year post-fire ecosystem condition" (2009). USDA Forest Service / UNL Faculty Publications. 195.

https://digitalcommons.unl.edu/usdafsfacpub/195

This Article is brought to you for free and open access by the U.S. Department of Agriculture: Forest Service -National Agroforestry Center at DigitalCommons@University of Nebraska - Lincoln. It has been accepted for inclusion in USDA Forest Service / UNL Faculty Publications by an authorized administrator of DigitalCommons@University of Nebraska - Lincoln. 


\section{Authors}

Leigh B. Lentile, Alistair M.S. Smith, Andrew T. Hudak, Penelope Morgan, Michael J. Bobbitt, Sarah A. Lewis, and Pete Robichaud 


\title{
Remote sensing for prediction of 1-year post-fire ecosystem condition
}

\author{
Leigh B. Lentile ${ }^{\mathrm{A}, \mathrm{D}, *}$, Alistair M. S. Smith ${ }^{\mathrm{B}, *}$, Andrew T. Hudak ${ }^{\mathrm{C}}$, \\ Penelope Morgan ${ }^{\mathrm{B}}$, Michael J. Bobbitt ${ }^{\mathrm{B}}$, Sarah A. Lewis ${ }^{\mathrm{C}}$ \\ and Peter R. Robichaud ${ }^{\mathrm{C}}$ \\ ${ }^{A}$ Department of Forestry and Geology, University of the South, Sewanee, TN 37383, USA. \\ ${ }^{B}$ Department of Forest Resources, University of Idaho, Moscow, ID 83844-1133, USA.

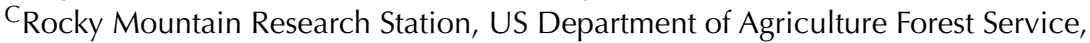 \\ Moscow, ID 83843, USA. \\ DCorresponding author. Email: Iblentil@sewanee.edu
}

\begin{abstract}
Appropriate use of satellite data in predicting $>1$ year post-fire effects requires remote measurement of surface properties that can be mechanistically related to ground measures of post-fire condition. The present study of burned ponderosa pine (Pinus ponderosa) forests in the Black Hills of South Dakota evaluates whether immediate fractional cover estimates of char, green vegetation and brown (non-photosynthetic) vegetation within a pixel are improved predictors of 1-year post-fire field measures, when compared with single-date and differenced Normalized Burn Ratio (NBR and dNBR) indices. The modeled estimate of immediate char fraction either equaled or outperformed all other immediate metrics in predicting 1-year post-fire effects. Brown cover fraction was a poor predictor of all effects $\left(\mathrm{r}^{2}<0.30\right)$, and each remote measure produced only poor predictions of crown $\operatorname{scorch}\left(\mathrm{r}^{2}<0.20\right)$. Application of dNBR $(1$ year post $)$ provided a considerable increase in regression performance for predicting tree survival. Immediate post-fire NBR or dNBR produced only marginal differences in predictions of all the 1-year post-fire effects, perhaps limiting the need for prefire imagery. Although further research is clearly warranted to evaluate fire effects data available 2-20 years after fire, char and green vegetation fractions may be viable alternatives to dNBR and similar indices to predict longer-term post-fire ecological effects.
\end{abstract}

Additional keywords: burn severity, char, Landsat ETM+, ponderosa pine, subpixel, unmixing.

\section{Introduction}

The large size and, in many cases, remote nature of many wildfires have made analysis of Earth observation imagery an important and widely applied method for immediate and longterm assessment of fire effects on ecosystems (Morgan et al. 2001; Lentile et al. 2006b). Appropriate use of remote sensing tools and techniques in predicting these fire effects, such as vegetation recovery and successional processes, requires that we investigate the mechanistic, biophysical relationships between remotely sensed metrics of post-fire surface condition, such as changes in reflectance, surface temperature, heights (e.g. using laser altimetry data) or fractional cover; with field measures of ecosystem condition (Key 2006; Lentile et al. 2006b). Definitions and assessments of post-fire ecosystem condition often use the word 'severity', which for the present paper will be described as 'burn severity' and includes changes in both soil and vegetation conditions as a result of fire (Lentile et al. 2006b).

Although early remote sensing research to infer the severity of fires focussed on metrics that could be both measured on the ground and inferred by the sensors, such as crown consumption or subsequent tree mortality (Patterson and Yool 1998; Miller and Yool 2002), recent research has predominantly focused on using the differenced Normalized Burn Ratio (dNBR: Key and Benson 2006) spectral index or variants thereof (Holden et al. 2005; Miller and Thode 2007). This spectral index effectively measures the relative degree of vegetation and soil char cover change between pre- and post-fire conditions (Smith et al. 2005; Lentile et al. 2006b). Within North American wildfires, these values have been evaluated predominantly against an ocular field assessment method termed the Composite Burn Index (CBI) (van Wagtendonk et al. 2004; Brewer et al. 2005; Cocke et al. 2005) with only limited studies modeling or evaluating regressions with specific biological or ecological measures of post-fire effects (De Santis and Chuvieco 2007; Hudak et al. 2007b; Robichaud et al. 2007; Smith et al. 2007b).

Although fundamentally an ocular measurement, CBI is an integrative measure of post-fire effects across under- and overstorey strata (Key and Benson 2006). Although it is not ideal to compare singular-date field measurements with changedetection indices (Dozier and Strahler 1983), the CBI methodology is often applied because the assessment of fire effects in wildland fires typically occurs in an opportunistic or a rapid response (Lentile et al. 2007a) fashion, which limits the likelihood of available prefire data (Lentile et al. 2006b). Although

*Leigh B. Lentile and Alistair M. S. Smith contributed equally to the present paper. 
widely applied by fire management in the production of burned area reflectance classification (BARC) maps and within the national Monitoring Trends in Burn Severity (MTBS) program (e.g. Cocke et al. 2005; Epting et al. 2005; Miller and Thode 2007), limitations in both the dNBR and CBI methodologies have been highlighted (Roy et al. 2006; Smith et al. 2007b):

(i) The CBI measure is calculated in a highly subjective and qualitative manner, with evaluations often conducted without explicit knowledge of prefire ecosystem condition (van Wagtendonk et al. 2004) but rather with unburned adjacent areas used as prefire surrogates (Lentile et al. 2006b).

(ii) dNBR often exhibits non-linear asymptotic relationships with CBI (van Wagtendonk et al. 2004; Cocke et al. 2005; Wimberly and Reilly 2007), which leads to scaling challenges. This effect further varies with ecosystem type (Epting et al. 2005) and with the spatial resolution of the satellite sensor (van Wagtendonk et al. 2004).

(iii) Contemporary remote sensing studies have shown that the spectral bands used to calculate NBR are not optimal to evaluate the degree of burning (Smith et al. 2005; Roy et al. 2006).

(iv) $\mathrm{dNBR}$ and CBI have been shown to be suboptimal in woodland, shrub and grassland environments (Epting et al. 2005; Roy et al. 2006; De Santis and Chuvieco 2007), resulting in studies considering variants of both CBI (Epting et al. 2005; De Santis and Chuvieco 2007) and dNBR, such as the relative dNBR (RdNBR), to assess post-fire effects (Miller and Thode 2007). Although other investigations show no improvement of RdNBR over dNBR when applied in environments dissimilar to those for which RdNBR was developed (Hudak et al. 2007b), it has the potential to provide consistently interpretable results across multiple environments (Miller and Thode 2007; Safford et al. 2007).

(v) The remote sensing literature has demonstrated the spectral changes that dNBR highlights are due to differences in the amount of vegetation, soil and char detected (Smith et al. 2005; Roy et al. 2006) and although it has been highlighted that dNBR predominantly detects changes in vegetation consumed (Hudak et al. 2007b) or killed (Miller and Thode 2007), disagreement exists within the fire ecology community as to whether dNBR maps should be used to only infer fire effects on soil and not on vegetation (Odion and Hanson 2006, 2007; Safford et al. 2007).

(vi) Contemporary studies have questioned whether studies should infer post-fire effects from the immediate postfire NBR, the immediate post-fire $\mathrm{dNBR}\left(\mathrm{NBR}_{\mathrm{pre}}-\right.$

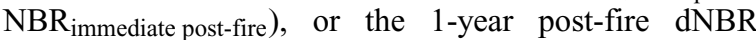
$\left(\mathrm{NBR}_{\text {pre }}-\mathrm{NBR}_{1-\text { year post-fire }}\right)$, which can lead to confusion when selecting methods for assessment (Epting et al. 2005; Hudak et al. 2007b). Specifically, some studies highlight dNBR (Epting et al. 2005) or conversely NBR (Bobbe et al. 2003; Hudak et al. 2007b) to be improved predictors of post-fire effects. Motivation for using dNBR or similar multitemporal imagery includes the potential to minimize classification errors due to sun-sensor geometry, atmospheric effects, phenology or areas that are spectrally flat such as water or older burns (Bobbe et al. 2003; De Santis and Chuvieco 2007).

(vii) Roy et al. (2006) highlighted that the original application of the dNBR was for burned area mapping (López-García and Caselles 1991), which relies on fundamentally opposite assumptions to methods used to assess a range of biophysical variation within an area (Verstraete and Pinty 1996; Roy et al. 2006), such as a range of 'severity' after a wildfire.

Specifically in terms of (vii), numerous authors have remarked that the ultimate goal of any land-cover classification approach is ideally to produce class histograms that are narrowly peaked (low internal variability) but that have well-separated means, such that the different class histograms are less likely to overlap and therefore would exhibit higher spectral separation (Verstraete and Pinty 1996; Pereira 1999; Roy et al. 2006). In contrast, when evaluating within-area effects, such as burn severity, a large dynamic range of within-class values is desired to provide detailed characterization of those effects. In essence, although well-separated class means are still desired, the user now needs the individual class histograms to be very wide, or at least exhibit bi- or tri-modal properties, to enable splitting of any particular class into distinct regimes, such as 'low, moderate and high'. When such bi- or tri-modal properties are not immediately apparent, it is common to use statistical breaks, such as those derived from training data (Pereira 1999; Hudak et al. 2007a).

As these are mutually exclusive objectives (Verstraete and Pinty 1996; Pereira 1999), dNBR and any other similar spectral index cannot be optimal for characterizing both burned area and post-fire effects related to severity (Roy et al. 2006). Owing to mixed results in the application of dNBR to severity assessments in a range of fire types outside the area around Glacier National Park, Montana, for which it was originally developed (Key 2006), it remains apparent that more research is needed to determine whether dNBR is better suited to the assessment of burn area or burn severity.

These factors potentially limit the wide-scale applicability of dNBR and similar spectral indices to infer post-fire ecosystem condition and highlight the continued need for further research to evaluate alternative and perhaps more appropriate remote sensing methods (Roy et al. 2006). Recent research has highlighted spectral mixture analysis (SMA) as one such alternative approach with potential to meet this need (Lentile et al. 2006b; Hudak et al. 2007b; Lewis et al. 2007; Smith et al. $2007 a, 2007 b$ ). To date, SMA (common synonyms: linear spectral unmixing, mixture modeling) has predominantly been used to map the extent of the burned area (Wessman et al. 1997; Cochrane and Souza 1998; Vafeidis and Drake 2005; Smith et al. $2007 a$ ). It also enables estimation of fractional cover components with each multispectral image pixel, including unburned vegetation (green or senesced), soils and charred or fully combusted vegetation (Smith and Hudak 2005; Smith et al. 2005; Lewis et al. 2007; Robichaud et al. 2007). Although other subpixel methods such as mixture tuned matched filtering (Robichaud et al.2007) and fuzzy classification methods exist (Foody 2000), SMA has widely been applied to the analysis of ecological data (Wessman et al. 1997) and its theory and limitations are well documented in the literature (Drake et al. 1999; Theseira 
et al. 2003). SMA relies on the assumptions of linear spectral mixing models (Drake et al. 1999) and thus the results are inherently scalable across data of different spatial resolutions (Settle and Drake 1993). SMA also can be applied to any type of imagery with multiple reflectance channels in the visible and near-infrared wavelength regions, without reliance on the availability of specific channels (e.g. bands 4 and 7 to calculate dNBR from Landsat Thematic Mapper (TM) or Enhanced Thematic Mapper Plus (ETM+)). Furthermore, it allows production of measures that are directly analogous to traditional 'field severity' assessments of \% green, \% brown and \% black (Lentile et al. 2006b).

Smith et al. (2007b) observed in a recent preliminary study that in comparison with the immediate post-fire metrics of dNBR and fractional green cover, the estimate of fractional char cover applied to a mixture of aspen and ponderosa pine plots produced marginally improved predictions of two 1-year post-fire effect measures (\% live trees and organic litter weight). However, in contrast, Hudak et al. (2007b) observed that green fractional cover was an equal or improved correlate to multiple postfire effects when compared with immediate post-fire NBR and dNBR. This conflicting result of Hudak et al. (2007b) could in part be due to the ponderosa pine and aspen stands exhibiting different spectral and fire effect characteristics, highlighting that these data be revaluated for single-species stands. Moreover, the apparent ability of a remote sensing method to reasonably predict a subcanopy post-fire effect offers considerable promise to remotely assess ecological indicators of the fire intensity and severity (Smith et al. 2007b). Therefore, further research is warranted to assess whether similar fractional cover estimates of the char, green vegetation and also senesced vegetation (or a mixture thereof), can also predict a wider range of both canopy and subcanopy post-fire effects, beyond the two 1-year post-fire measures previously evaluated. Therefore, following on from Smith et al. (2007b) and Hudak et al. (2007b), the objectives of the present study are:

(1) Evaluate whether SMA-derived estimates of fractional char, green and brown vegetation covers immediately post-fire are improved predictors, over immediate NBR and dNBR, for a wide variety of both canopy (four) and subcanopy (nine) ecological indictors measured in 66 ponderosa pine plots 1 year after fire;

(2) Evaluate whether these immediate fractional measures are improved correlates of 1-year post-fire conditions when compared with dNBR calculated from pre- and 1-year post-fire imagery;

(3) Evaluate the degree of redundancy (if any) due to the different fractional cover measures when predicting the 1-year post-fire effects. This will enable us to evaluate whether a combination approach based on several different cover metrics has potential; and

(4) Evaluate whether any improvement in prediction performance is achieved by using the immediate post-fire dNBR over NBR. Although applications of dNBR are widely presented to managers via BARC maps, this analysis will enable us to determine whether the prefire imagery provides additional information in predicting longer-term post-fire effects.

\section{Methods}

Study area

The current study focussed on the $\sim 33800$-ha Jasper Fire, which occurred in 2000 in the Black Hills of western South Dakota, USA. Within the fire, latitudes range from $43^{\circ} 41^{\prime} 35^{\prime \prime}$ to $43^{\circ} 55^{\prime} 48^{\prime \prime} \mathrm{N}$ and longitudes range from $103^{\circ} 46^{\prime} 1^{\prime \prime}$ to $104^{\circ} 0^{\prime} 47^{\prime \prime} \mathrm{W}$. Elevations range from $\sim 1500$ to $2100 \mathrm{~m}$. The Black Hills are an isolated mountain range on the Northern Great Plains physiographic province in western South Dakota and northeastern Wyoming (Fig. 1). As the easternmost extension of the Rocky Mountains, the Black Hills were formed by regional uplift between $\sim 35$ and 65 million years ago. This uplift produced an elliptical dome with an older crystalline core surrounded by younger, steeply dipping sedimentary deposits (Shepperd and Battaglia 2002). The Limestone Plateau surrounds the core and the area burned by the Jasper Fire is located on the south-western extent of this fertile plateau. The area within the Jasper Fire perimeter is characterized by relatively continuous ponderosa pine (Pinus ponderosa) stands, although occasional quaking aspen (Populus tremuloides Michx.) clones and grasslands also exist. A complete description of the study area and fire regime is provided in Lentile (2004) and Lentile et al. (2005).

\section{Remote sensing data and methods}

Three Landsat ETM+ images of the study area were acquired (18 August 1999; 14 September 2000; 24 September 2001). Each image was corrected to top-of-atmosphere reflectance using the standard calibration equations. The Normalized Burn Ratio (NBR), defined as the normalized difference of Landsat bands 4 and 7 (band 4 - band7)/(band 4 + band7), was then determined for each image. Two forms of dNBR were applied, namely the 'immediate dNBR', which used the prefire and immediate post-fire image, and the ' 1 -year post-fire dNBR', which, as the name suggests, used the prefire and 1-year postfire image in the dNBR calculation. Both the immediate dNBR and 1-year post-fire dNBR were calculated by subtracting the post-fire image from the prefire image. Rather than classifying dNBR values using arbitrary thresholds, we used the continuous dNBR values in subsequent regression analyses. Following Cocke et al. (2005), each dNBR image was then scaled by multiplying each value by 1000 . For this analysis, the immediate post-fire Landsat ETM+ imagery was additionally converted into ground-reflectance using the standard method of 'dark-body subtraction' using the minimum-band pixel values as selected by the ITT Visual Information Systems for ENVI software package (ITT Visual Information Solutions, Boulder, CO, USA).

The estimation of the fractional cover of char (Fig. 1), brown vegetation and green vegetation within each Landsat pixel was determined using spectral mixture analysis (Settle and Drake 1993). Although other linear and non-linear spectral unmixing methods have been applied to the assessment of post-fire affected surfaces (Smith et al. 2005; Robichaud et al. 2007), the accuracy and ease of implementation of linear compared with the complexity of non-linear models has led to the widespread adoption of linear SMA in Earth observation studies (Drake et al. 1999; Chen et al. 2004). Importantly, the principal assumption of linear mixture models, namely that a mixture of $50 \%$ of $A+50 \%$ of $B$ will have a spectral reflectance of $((\mathrm{A}+\mathrm{B}) / 2)$ over all analyzed 


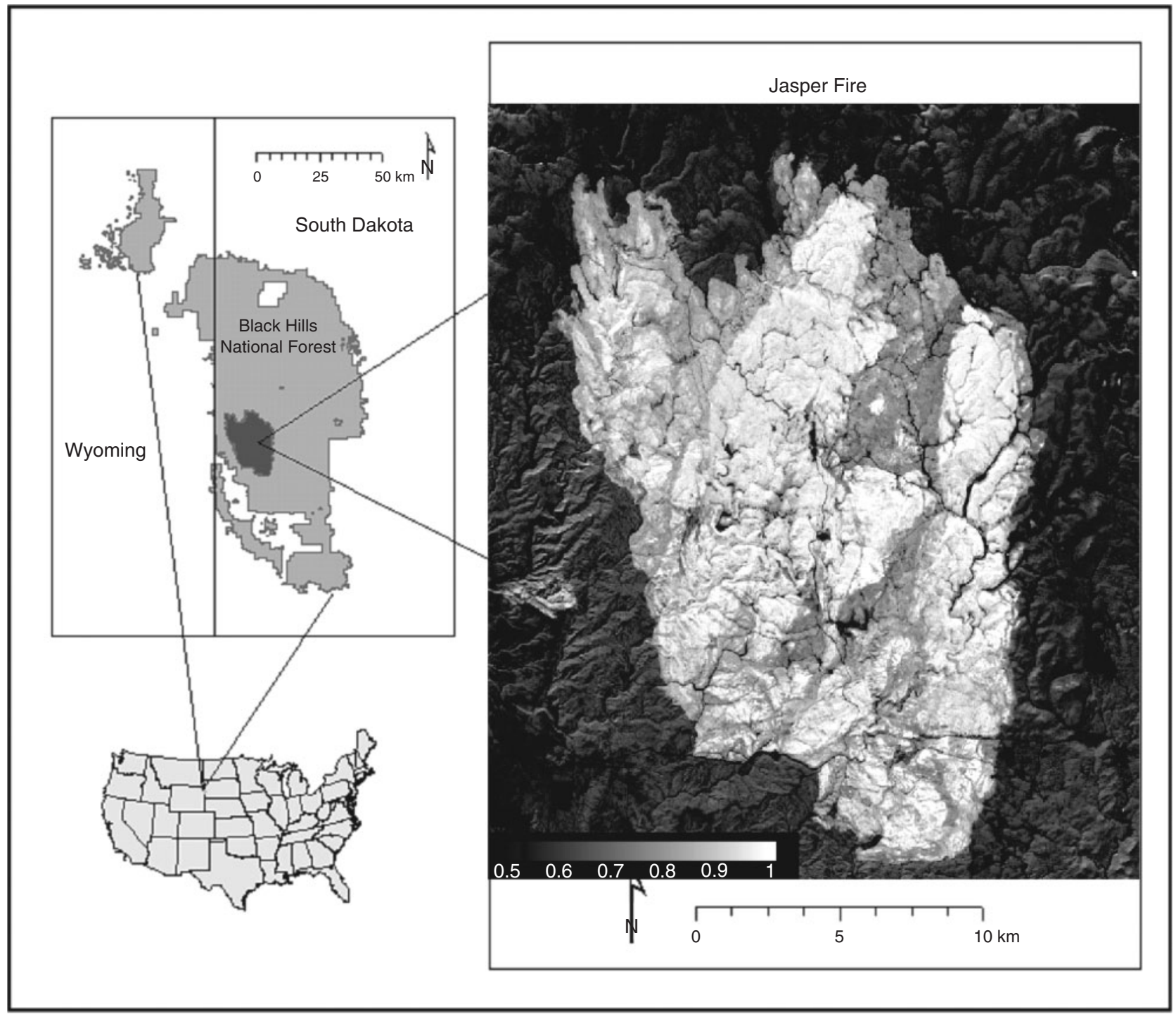

Fig. 1. The location of the Jasper Fire, South Dakota (USA). The image insert is the fractional char cover image produced using the immediate post-fire Landsat image.

wavelengths (e.g. $0.3-2.5 \mu \mathrm{m}$ ), has been shown to be broadly valid when considering mixtures of unburned and burned surface components (Cochrane and Souza 1998; Smith et al. 2005; Vafeidis and Drake 2005). The classical linear spectral unmixing model is defined by Theseira et al. (2002) as:

$$
R_{n}=\sum_{c=1}^{n}\left(a_{n c} x_{c}\right)+e_{n}
$$

where, $R_{n}$ is the reflectance of the pixel in the $n$th spectral band, $x_{c}$ is the proportion of the $c$ th component in the pixel, $a_{n c}$ is the spectral endmember of the $c$ th component for the $n$th spectral band and $e_{n}$ denotes the pixel noise term.

Generic spectra of senesced vegetation, green vegetation and char (Fig. 2) were used as the authors of several past studies have remarked that these spectral reflectance curves are broadly similar across a wide range of environments (Elvidge 1990;
Landmann 2003; Smith et al. 2005, 2007a, 2007b; Hudak et al. 2007b). As detailed by Smith et al. (2005), the spectral reflectance functions for representative green vegetation, senesced grasses and char (among other surfaces) were collected with a GER-3700 spectroradiometer (Spectravista Corporation, Poughkeepsie, NY). The GER-3700 was set up at a height of $0.75 \mathrm{~m}$ directly above (i.e. at nadir) the vegetation and char samples. Measurements were acquired in full sunlight within a $3^{\circ}$ field of view; for each spectrum, eight spectral measurements were acquired over a 5-s interval and the mean calculated. Furthermore, for each sample of vegetation and char (five of each), three such sets of measurements were acquired from different vantage points to capture variability due to shading and increase the signal-to-noise ratio of the resultant spectral reflectance curves. The spectral radiance measurements were converted into reflectance by normalizing the response against a Spectralon reflectance panel (Labsphere, North Sutton, NH, USA), 


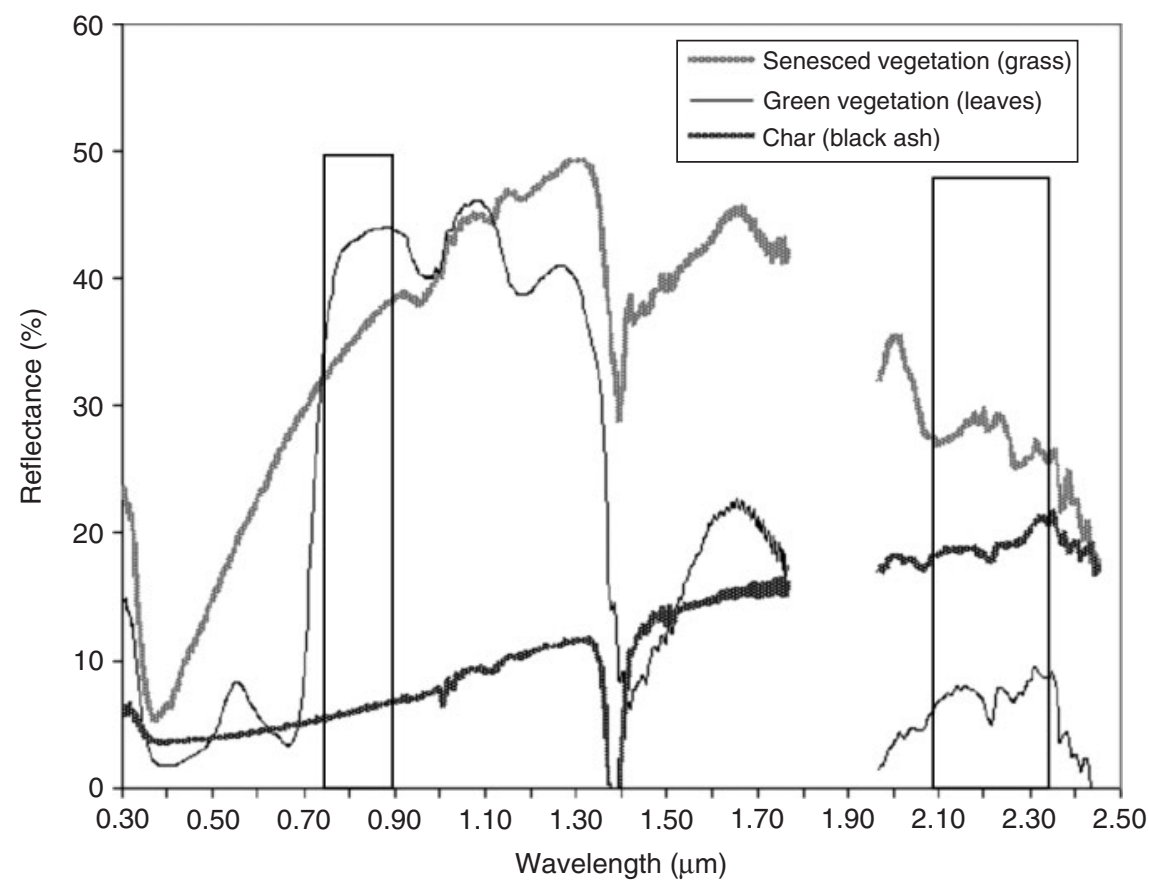

Fig. 2. Generic spectral reflectance curves of green vegetation, senesced vegetation, and char (black ash). Spectra were acquired by Smith et al. (2005). The data gap $\sim 1.8 \mu \mathrm{m}$ represents the dominant water absorption feature where data quality is insufficient for analysis. The two shaded columns highlight the general wavelength ranges of Landsat band $4(0.76-0.90 \mu \mathrm{m})$ and band $7(2.08-2.35 \mu \mathrm{m})$ for both Landsat Thematic Mapper (TM) or Enhanced Thematic Mapper (ETM).

which provides near $100 \%$ reflectance over all the $0.3-2.5-\mu \mathrm{m}$ wavelengths.

As outlined in Smith et al. (2007b), the spectral components of green vegetation, senesced or non-photosynthetic vegetation and charcoal were selected as they are ubiquitous surface characteristics that are present in most global savanna-type fire-prone environments. We acknowledge that application of non-site- and species-specific spectral reflectance curves may not provide an optimal unmixing result. However, these generic spectra were applied as we sought to explore surface components that could potentially be quickly applied to global savanna-type fires to assess post-fire effects. A common spectral component used in spectral mixture analysis is that of the dominant soil. However, we deliberately sought non-soil components, as (1) soils types are highly variable within individual fires, let alone across a series of fires, and (2) soil spectra vary considerably between different soil types and in soils with varying organic or moisture characteristics (Huete and Escadafal 1991; Nagler et al. 2000). In the present study, we did not consider shade as an endmember as it does not have a unique spectral reflectance curve, but rather exhibits a range of curves associated with ever-darkened versions of the surface component being shaded. We acknowledge that in future regional fires, using locally collected spectral data would be most appropriate. For example, for a detailed comparison of spectral endmembers from other wildfires, please refer to the Fire Research and Management Exchange System (FRAMES) online resource. FRAMES can be accessed at http://frames.nbii.gov/ (accessed 26 January 2008). The endmembers can be accessed using keywords 'Spectral Library'.
Linear spectral unmixing was applied using the $I D L / E N V I$ ver 4.2 module with the 'sum to 1' constraint applied (Drake et al. 1999), which ensures that all component fractions within a pixel sum to unity, although individual class fractions may be negative or exceed 1. To input the spectral reflectance curves for use in the ITT Visual Information Systems for the ENVI software package, it was first necessary to interpolate the spectral data to $1-\mathrm{m}$ steps and then convolve the data with the band spectral response functions of the Landsat 7 sensor (Smith et al. $2005)$. This provides $E N V I$ with six values, where each value corresponds to the associated reflectance bands, rather than 2300 continuous values. The wavelength ranges associated with bands 4 and 7 (i.e. the NBR bands) of the Landsat sensors are shown in Fig. 2.

Each individual band reflectance, dNBR and associated fractional cover estimate was then extracted at each plot location using the $A R C$ software package (ESRI, Redlands, CA, USA).

\section{Field measurements}

Lentile (2004) and Keyser (2007) sampled three 800-ha study areas that contained a mosaic of fire effects in the north, central and southern portions of the Jasper Fire perimeter. In June 2001, before the fall of fire-scorched needles, 66 0.28-ha (30-m radius) permanent study sites were established in ponderosa pine stands within the study areas. Within these burned stands, nine sites were located in areas exhibiting evidence of surface fire behavior with low initial post-fire tree mortality; 24 sites were located in ponderosa pine stands exhibiting moderate 
Table 1. Direct fire effects measured on the boles and in crowns of trees after the Jasper Fire

All values are mean \pm standard error $(n=66)$. All were significant at the $99 \%$ confidence interval

\begin{tabular}{|c|c|c|c|c|c|c|}
\hline Burn severity $(\%)$ & Crown scorch $(\%)$ & Crown consumption $(\%)$ & Bole scorch at $1 \mathrm{~m}(\%)$ & Bole scorch $(\%)$ & Basal scorch (\%) & Basal char $(\%)$ \\
\hline Low & $19.5(3.3)$ & $0.1(0.1)$ & $15.2(2.1)$ & $35.3(7.6)$ & $80.2(4.1)$ & $8.7(3.6)$ \\
\hline Moderate & $69.7(4.3)$ & $4.9(2.2)$ & $41.9(3.2)$ & $87.1(2.6)$ & $79.3(6.2)$ & $19.2(6.2)$ \\
\hline High & $8.8(7.3)$ & $90.6(7.3)$ & $99.7(0.2)$ & $99.9(0.1)$ & $48.2(9.3)$ & $51.8(9.3)$ \\
\hline
\end{tabular}

fire behavior, consisting of surface fire with individual tree torching resulting in moderate initial post-fire tree mortality; and 33 were located in severely burned ponderosa pine stands where all trees were killed. Each site consisted of three 0.031-ha (10-m radius) plots. Plots were located at bearings $0^{\circ}, 135^{\circ}$ and $225^{\circ}$ azimuth $20 \mathrm{~m}$ from the site center. Study sites were similar in respect to preburn species composition, aspect, slope (5-13\%), elevation and soil type (Lentile 2004; Keyser et al. 2006; Lentile et al. 2006a; Keyser 2007). These data were recently presented in combination with 14 additional aspen study sites within a preliminary assessment of char fraction measures (Smith et al. $2007 b$ ). Prior studies have observed that pine and aspen plots differ in their spectral properties and response to fire (Brown and Smith 2000; Keyser et al. 2005), so the present study excluded the aspen plots from the analysis.

On these plots, data on the fire effects on the canopy, boles and around the bases of individual trees $>5 \mathrm{~cm}$ diameter at breast height $(\mathrm{DBH})(1.4 \mathrm{~m}$ above soil surface) were collected (Table 1). Tree survival was calculated based on the proportion of trees surviving the fire compared with trees alive before the fire on each plot (\% live tree). Trees with no green foliage were considered dead. Bark thickness was sampled at breast height at two different locations on the bole to compute an average bark thickness per tree. In addition, we measured total tree height and prefire crown base height. Crown base height was measured at the point of branch-bole attachment of the lowest prefire live whorl. We identified prefire crown base height from the position of scorched needles in the case where no foliage consumption occurred and fine branch structure in the case where consumption of needles occurred. Scorched needles were easily distinguishable from non-scorched needles as they were brown or orange in color. Crown injury was measured on individual trees and included the proportion of the prefire live crown that was affected by crown scorch (\% crown scorch) or crown consumption ( $\%$ crown consumption). The cumulative effects of crown scorch and consumption are represented by the total crown fire effects. We measured the percentage of the bole circumference scorched below $30 \mathrm{~cm}$ above the soil to the nearest $5 \%$ as an indicator of stem damage (basal scorch \%). We measured the percentage of the bole circumference charred below $30 \mathrm{~cm}$ to the nearest $5 \%$ as an indicator of stem and cambial damage (basal char \%). Charred bark was distinguished from scorched bark as it was metallic black in color (similar to the color and texture of charcoal) and was eroded to the point that the bark no longer contained grooves or furrows, whereas scorched bark was completely intact and black or gray in color We measured the percentage of the bole circumference scorched at $100 \mathrm{~cm}$ to the nearest $5 \%$ as an indicator of stem damage (bole scorch at $1 \mathrm{~m} \%$ ). For further details, see Lentile (2004), Keyser et al. (2006) and Keyser (2007). A typical ponderosa pine stand 1 year following the Jasper Fire is shown in Fig. 3.

Following Ryan and Noste (1985), the percentage low, moderate and high ground char in a 1-m radius area around the base of each tree was measured. Line transects $(30 \mathrm{~m})$ were laid at $90^{\circ}$ and $270^{\circ}$ bearings with the site center as the midpoint. Depths of forest floor litter and duff and the percentage low, moderate and high ground char (Ryan and Noste 1985) for a $0.025-\mathrm{m}^{2}$ surface area were measured at 30 points at 2-m intervals along these transects. An index of burn severity (BI) was defined as a weighted sum of the product of the proportion of the ground area charred, with the degree of char scaled from low (1) to high (3). Within each of the individual tree plots, we characterized the forest floor and soil effects. As these measurements were not originally intended for the purposes of a char or remote sensing analysis, we assigned a proportion low, moderate and high burn severity based on widely applied descriptions of field severity (Ryan and Noste 1985). To calculate the Burn Index, we multiplied the \% low times 100; the \% moderate times 200; and the $\%$ high times 300 ; and then summed these scores. BI was calculated within a $1-\mathrm{m}$ radius area around the base of each tree within plots (Total BI $1 \mathrm{~m}$ tree), and for each of the 30 forestfloor points located at 2-m intervals along the transect (Floor BI). At six additional points offset from the transect, samples were collected, and later oven-dried and weighed to estimate forest floor biomass (litter organic weight). This same suite of measurements was conducted at nine adjacent, unburned sites in order to provide an estimate of fire-induced changes on the forest floor.

\section{Statistical analysis}

Simple linear regressions were applied to assess the predictive ability of the fractions and NBR indices to predict the 1-year post-fire effects. The regressions were tested for significance at the 95\% level and the standard error calculated (Tables 2-4). Linear regressions were also determined to assess the ability of 1-year post-fire dNBR to indicate 1-year post-fire effects. Furthermore, both single and multiple linear regressions were applied within the SPSS software package (SPSS Inc., Chicago, IL) to assess the degree of redundancy in the information provided by each of the fractional cover measures in predicting the 1-year post-fire effect measures (Table 5).

\section{General limitations of pixel-based remote sensing methods and SMA}

Two main limitations exist when relating pixel-based remotely sensed data to ecological effects, namely assumed independence of neighboring pixels and that the observed signal only represents 


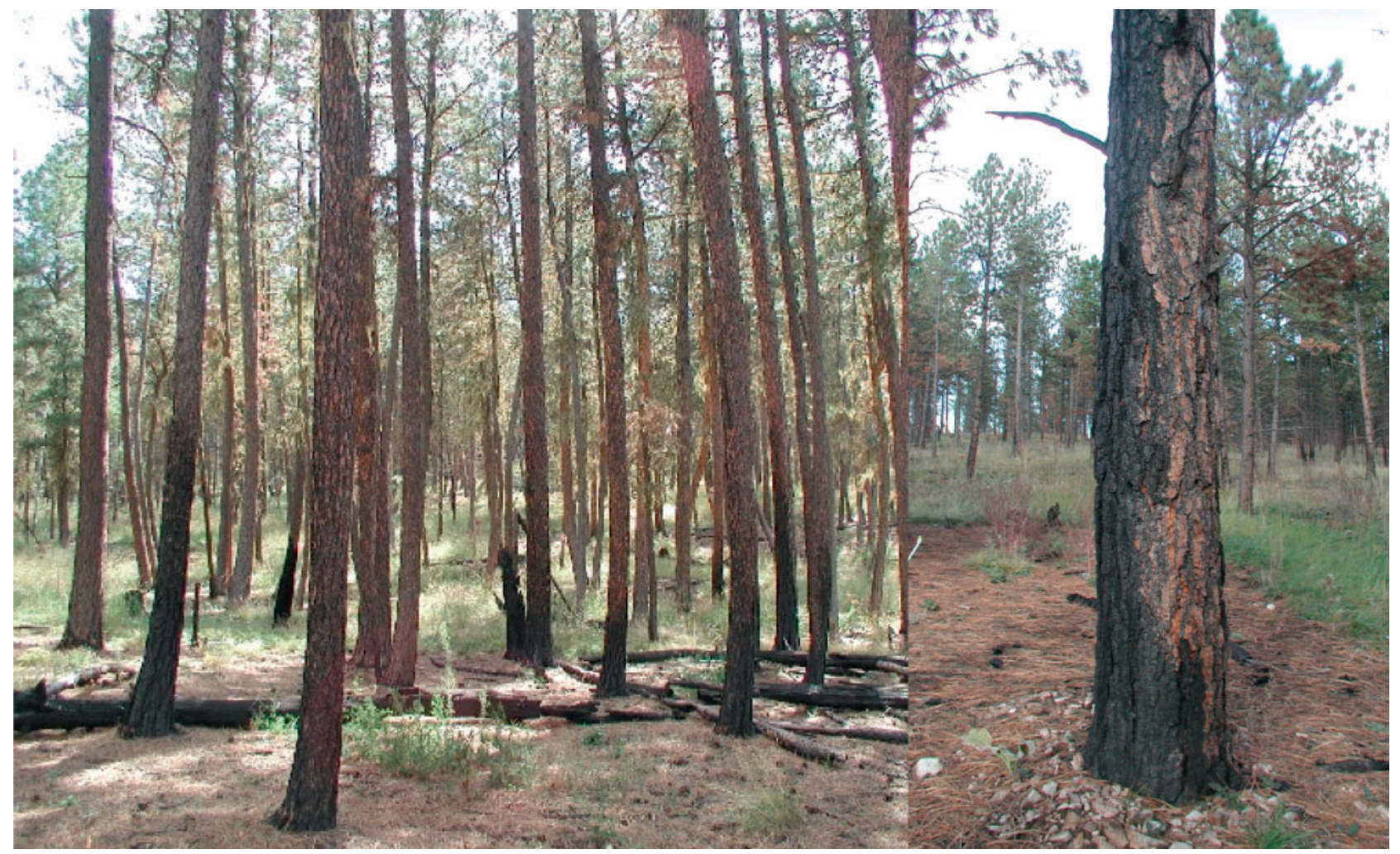

Fig. 3. Left image shows a 1-year post-fire view of a ponderosa pine forest burned by non-stand replacing fire. Right image highlights a typical scorched bole, as measured in the field.

Table 2. Prediction statistics $(n=66)$ between immediate post-fire char and green (live vegetation) fractions with 1-year post-fire field measures All regressions, except those denoted by **, were significant at the $95 \%$ level. s.e. denotes the standard error of the estimate. Prediction statistics are between immediate post-fire remote fractional measures (char fraction, green vegetation fraction) with 1-year post-fire field measures. BI, Burn Severity Index

\begin{tabular}{|c|c|c|c|c|c|c|}
\hline \multirow[t]{3}{*}{ Ground predictor (y) } & \multicolumn{6}{|c|}{ Remote measures (x) } \\
\hline & \multicolumn{3}{|c|}{ Fraction char cover } & \multicolumn{3}{|c|}{ Fraction green cover } \\
\hline & $r^{2}$ & s.e. & Equation & $\mathrm{r}^{2}$ & s.e. & Equation \\
\hline \multicolumn{7}{|l|}{ Canopy variables } \\
\hline \% Live tree & 0.69 & 23.17 & $-483 \times x+487$ & 0.59 & 25.65 & $254 \times x-15$ \\
\hline Crown scorch & 0.17 & 31.73 & $-201 \times x+224$ & $* *$ & & \\
\hline Crown consumption & 0.65 & 26.25 & $499 \times x-422$ & 0.42 & 33.83 & $-227 \times x+89$ \\
\hline Total crown fire effects & 0.57 & 18.88 & $298 \times x-197$ & 0.55 & 19.16 & $-168 \times x+114$ \\
\hline \multicolumn{7}{|l|}{ Subcanopy variables } \\
\hline Bole scorch & 0.72 & 18.27 & $411 \times x-318$ & 0.60 & 22.12 & $-212 \times x+108$ \\
\hline Basal char & 0.33 & 28.77 & $277 \times x-206$ & 0.32 & 28.82 & $-157 \times x+84$ \\
\hline Basal scorch & 0.21 & 4.81 & $35 \times x+65$ & 0.16 & 4.97 & $-17 \times x+101$ \\
\hline Average bark thickness & 0.48 & 0.28 & $-3.6 \times x+4.3$ & 0.35 & 0.32 & $1.8 \times x+0.51$ \\
\hline Bole scorch at $1 \mathrm{~m}$ & 0.43 & 20.29 & $243 \times x-144$ & 0.44 & 20.02 & $-141 \times x+112$ \\
\hline Total BI $1 \mathrm{~m}$ tree & 0.64 & 36.96 & $289 \times x-396$ & 0.56 & 41.12 & $-365 \times x+320$ \\
\hline Floor BI & 0.44 & 49.37 & $607 \times x-339$ & 0.31 & 55.04 & $-277 \times x+284$ \\
\hline Litter depth & 0.49 & 0.24 & $-3.4 \times x+3.5$ & 0.39 & 0.27 & $1.7 \times x+0.04$ \\
\hline Litter organic weight & 0.71 & 3.99 & $-80 \times x+82$ & 0.64 & 4.40 & $44 \times x-1.70$ \\
\hline
\end{tabular}

the spectral contributions of the components that occupy that specific pixel (Cracknell 1998; Townshend et al. 2000). These problems arise from the arbitrary definition of a pixel: a typically square unit somewhat related to the circular field of view of the optical sensor that will likely not have edges matching 
Table 3. Prediction statistics $(n=66)$ between immediate post-fire brown (senesced vegetation) fraction and immediate post-fire Normalized Burn Ratio (NBR) with 1-year post-fire field measures

All regressions, except those denoted by **, were significant at the $95 \%$ level. s.e. denotes the standard error of the estimate. BI, Burn Severity Index

\begin{tabular}{|c|c|c|c|c|c|c|}
\hline \multirow[t]{3}{*}{ Ground predictor (y) } & \multicolumn{6}{|c|}{ Remote measures (x) } \\
\hline & \multicolumn{3}{|c|}{ Fraction brown cover } & \multicolumn{3}{|c|}{ Immediate post-fire NBR } \\
\hline & $\mathrm{r}^{2}$ & s.e. & Equation & $\mathrm{r}^{2}$ & s.e. & Equation \\
\hline \multicolumn{7}{|l|}{ Canopy variables } \\
\hline$\%$ Live tree & 0.24 & 36.37 & $-270 \times x+0.6$ & 0.54 & 28.44 & $0.11 \times x+52.69$ \\
\hline Crown scorch & $* *$ & & & 0.07 & 33.71 & $0.03 \times x+41.95$ \\
\hline Crown consumption & 0.1 & 42.22 & $13 \times x+39$ & 0.43 & 33.67 & $-0.10 \times x+27.79$ \\
\hline Total crown fire effects & 0.28 & 24.36 & $196 \times x+107$ & 0.50 & 20.25 & $-0.71 \times x+69.74$ \\
\hline \multicolumn{7}{|l|}{ Subcanopy variables } \\
\hline Bole scorch & 0.23 & 30.56 & $218 \times x+94$ & 0.53 & 23.81 & $-0.09 \times x+52.05$ \\
\hline Basal char & 0.16 & 32.12 & $186 \times x+77$ & 0.31 & 29.11 & $-0.07 \times x+42.30$ \\
\hline Basal scorch & $* *$ & & & 0.17 & 4.952 & $-0.01 \times x+96.82$ \\
\hline Average bark thickness & 0.11 & 0.37 & $-1.6 \times x+0.7$ & 0.40 & 0.31 & $0.001 \times x+0.99$ \\
\hline Bole scorch at $1 \mathrm{~m}$ & 0.24 & 23.43 & $171 \times x+106$ & 0.31 & 22.27 & $-0.53 \times x+75.53$ \\
\hline Total BI $1 \mathrm{~m}$ tree & 0.23 & 54.16 & $392 \times x+299$ & 0.54 & 41.89 & $-0.16 \times x+223.21$ \\
\hline Litter depth & 0.14 & 0.32 & $-1.7 \times x+0.2$ & 0.39 & 0.27 & $0.001 \times x+0.50$ \\
\hline Litter organic weight & 0.28 & 6.23 & $-48 \times x+1$ & 0.57 & 4.83 & $0.02 \times x+10.06$ \\
\hline
\end{tabular}

Table 4. Prediction statistics $(n=66)$ between immediate and 1-year post-fire differenced Normalized Burn Ratio (dNBR) with 1-year post-fire field measures

All models were significant at the $95 \%$ confidence level. s.e. denotes the standard error of the estimate. BI, Burn Severity Index

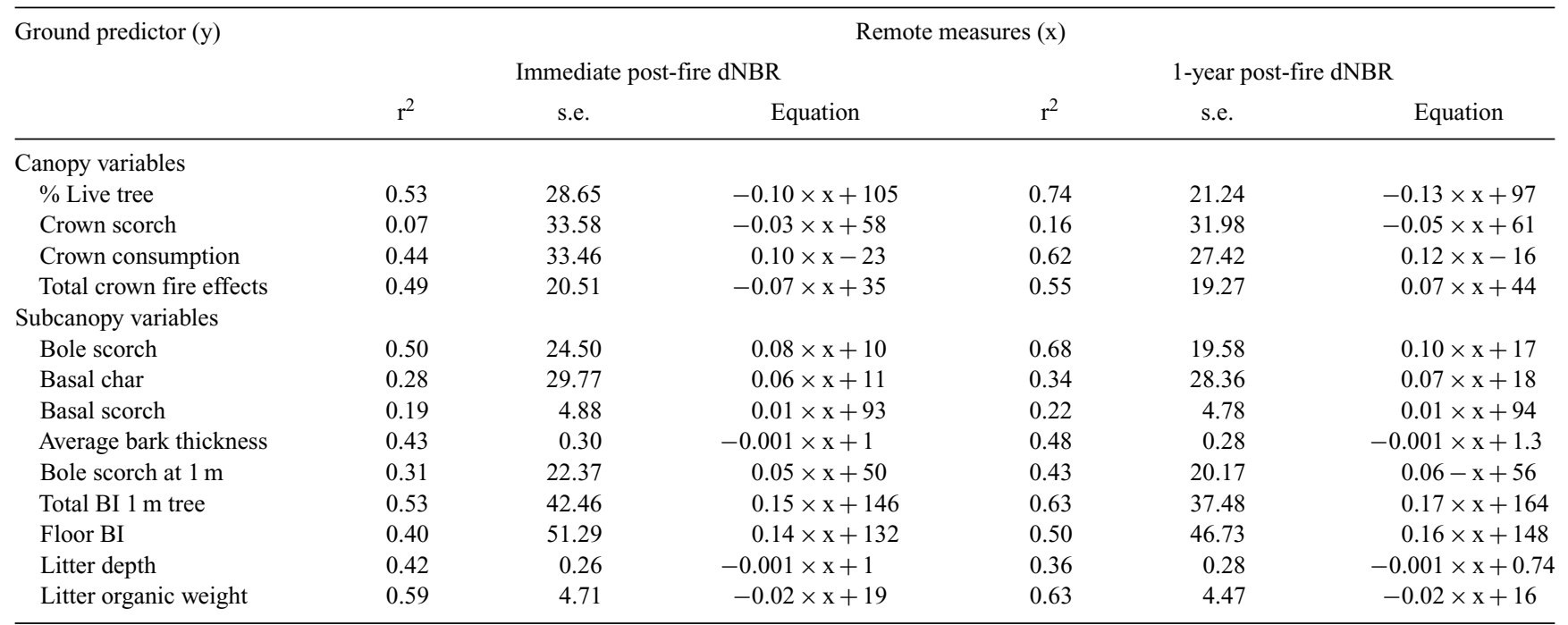

up with actual ecological or physical boundaries (Foody et al. 1997; Cracknell 1998). As a result, unless the relative contributions of surface components are inferred, assumption of a homogeneous pixel can lead to classification and subsequent model propagation errors (Foody et al. 1997).

The principal assumption specific to spectral mixture analysis is that the combined reflectance of the pixel is a 'linear combination' of the reflectances of the individual pixel components, weighted by the relative proportion they occupy in the pixel (Drake and White 1991; Settle and Drake 1993; Foody et al. 1997). In general, the linear mixing assumption is valid when the surface components exist as sufficiently large discrete areas that are optically thick (i.e. no light is transmitted through to a lower land-cover type), such that the photons only interact with a single land-cover type (Drake et al. 1999; Qin and Gerstl 2000). However, non-linear mixing does occur in environmental applications (Borel and Gerstl 1994), but can be minimized by using visible and short-wave infrared wavelengths $(0.3-2.5 \mu \mathrm{m})$ associated with low canopy transmissions (Drake et al. 1999).

Clark and Lucey (1984) observed that mixtures containing dark and light components mix non-linearly owing to the multiple scatters being preferentially reflected by lighter surfaces and 
Table 5. Prediction statistics $(n=66)$ between immediate post-fire remote fractional measures (char fraction, green vegetation fraction) with 1-year post-fire field measures

All regressions, except those denoted by $* *$, were significant at the $95 \%$ level. s.e. denotes the standard error of the estimate. BI, Burn Severity Index

\begin{tabular}{|c|c|c|c|c|}
\hline \multirow[t]{3}{*}{ Ground predictor $(\mathrm{y})$} & \multicolumn{4}{|c|}{ Fraction char cover and fraction green cover } \\
\hline & \multirow[t]{2}{*}{$r^{2}$} & \multirow[t]{2}{*}{ s.e. } & \multicolumn{2}{|c|}{ Significance } \\
\hline & & & Char fraction & Green fraction \\
\hline \multicolumn{5}{|l|}{ Canopy variables } \\
\hline$\%$ Live tree & 0.71 & 22.75 & 0.00 & $* *$ \\
\hline Crown scorch & 0.23 & 30.82 & 0.00 & 0.03 \\
\hline Crown consumption & 0.66 & 26.32 & 0.00 & $* *$ \\
\hline Total crown fire effects & 0.61 & 18.13 & 0.01 & 0.02 \\
\hline \multicolumn{5}{|l|}{ Subcanopy variables } \\
\hline Bole scorch & 0.74 & 18.09 & 0.00 & $* *$ \\
\hline Basal charring & 0.35 & 28.44 & $* *$ & $* *$ \\
\hline Basal scorch & 0.22 & 4.85 & 0.049 & $* *$ \\
\hline Average bark thickness & 0.48 & 0.29 & 0.001 & $* *$ \\
\hline Bole scorch at $1 \mathrm{~m}$ & 0.47 & 19.65 & $* *$ & 0.03 \\
\hline Total BI $1 \mathrm{~m}$ tree & 0.66 & 36.36 & 0.00 & $* *$ \\
\hline Floor BI & 0.44 & 49.78 & 0.00 & $* *$ \\
\hline Litter depth & 0.50 & 0.25 & 0.001 & $* *$ \\
\hline Litter organic weight & 0.73 & 3.83 & 0.00 & 0.03 \\
\hline
\end{tabular}

absorbed by darker surfaces. Such examples lead to the appearance of greater proportions of darker components within a pixel than actually exist (Foody et al. 1997). However, as noted earlier in the text, post-fire mixtures including the extreme 'real' ecological examples of white mineral ash $(>70 \%$ reflectance $)$ and black char ( $<20 \%$ reflectance) have been shown to be approximated to a generally linear mixture model (Smith et al. 2005). A further limitation of spectral mixture analysis is that unique spectral endmembers are required for each land cover class and the results are highly sensitive to how those endmembers are selected (Atkinson et al. 1997; Theseira et al. 2003). Errors can also arise when endmember spectra are missing or incorrectly defined.

\section{Results}

General description of post-fire effects

The direct and cumulative effects of fire on ponderosa pine trees were much greater on high-severity than on low- or moderateseverity sites (Table 1). Approximately 1, 22 and $100 \%$ of trees that were alive before the fire were killed in pine stands burned by low-, moderate- and high-severity fire. The entire bole was scorched, and canopy foliage and small branches were completely consumed in areas of high-severity fire. Bole and crown scorch was more extensive on moderate- than on lowseverity sites. Approximately $75 \%$ of the crown was scorched or consumed on moderate-severity compared with $\sim 20 \%$ on lowseverity sites. On average, $80 \%$ of the base of each tree bole was scorched on low- and moderate-severity sites, and 2.2 times more char was found on the base of each tree on moderate-severity sites relative to low-severity sites. Post-fire bark thickness (s.e.) was $1.5(0.1), 1.2(0.1)$ and $0.7(0.1) \mathrm{cm}$ in low-, moderate- and high-severity sites.
Fire effects on the forest floor were most substantial in areas of high burn severity where litter and duff were almost completely consumed. Total 'BI $1 \mathrm{~m}$ tree' was 141 on low-, 223 on moderate- and 290 on high-severity sites on a BI scale of 100 to 300 . Floor BI was 119 on low-, 186 on moderate- and 246 on high-severity sites on the same BI scale. Average litter depths (s.e.) were $1.2(0.3), 0.5(0.2)$ and $0.2(0.1) \mathrm{cm}$ on low-, moderateand high-severity compared with $4.8(0.5) \mathrm{cm}$ on unburned sites. Fire reduced litter depths by $\sim 76,91$ and $97 \%$ on low-, moderateand high-severity sites 1 year after fire. On average, there were 2.3 and 6.6 times more duff on unburned sites than on sites burned with low and moderate severity. No duff remained 1 year after fire on high-severity sites. Litter organic weights (s.e.) were 1266 (264), 684 (173), 459 (93) and 82 (45) $\mathrm{g} \mathrm{m}^{-2}$ in unburned, low-, moderate- and high-severity sites.

\section{Prediction of 1-year post-fire effects}

Fractional char cover either equaled or outperformed all other remote metrics as a predictor of 1-year post-fire effects, except for the relation between 1-year post-fire dNBR and percentage live tree $\left(r^{2}=0.74\right)$ (Tables $\left.2-4\right)$. Each remote metric poorly characterized crown scorch, with the char fraction and dNBR methods producing statistically significant but poor relationships $\left(\mathrm{r}^{2}<0.17, P<0.031\right)$. The 1 -year post-fire crown scorch on trees will likely be similar to scorch measured immediately post-fire. The results illustrate that fractional char cover is a reasonable predictor of several canopy and subcanopy measures (but not all: Tables 2, 3). In terms of canopy measures, fractional char cover produced reasonable predictions of \% live trees $\left(r^{2}=0.69\right)$ and $\%$ crown consumption $\left(r^{2}=0.65\right)$, and was comparable with the results obtained using the 1 -year postfire dNBR measure. However, the improved performance of the 1-year post-fire dNBR measure might be expected because both the imagery and field measures are effectively coincident measures of the same condition. In terms of subcanopy measures, fractional char cover strongly predicted $\%$ bole scorch $\left(\mathrm{r}^{2}=0.72\right)$ and weight of organic litter $\left(\mathrm{r}^{2}=0.71\right)$, while fractional green cover produced weaker but reasonable predictions $\left(r^{2}=0.60\right.$ and $r^{2}=0.64$ respectively). Both the char and green cover fraction predictions surpassed the immediate post-fire dNBR predictions of these 1-year post-fire effects.

When we compared the immediate post-fire NBR with immediate post-fire dNBR, inclusion of the prefire data did not improve the prediction of the 1-year post-fire measures, except for marginal improvements in predicting \% bole scorch $\left(\mathrm{r}^{2}=0.53\right)$. As it is not possible for any spectral ratio like dNBR to outperform a regression containing both of the two component bands (Lawrence and Ripple 1998), which in this case

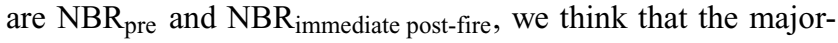
ity of the useful predictive information is contained within the

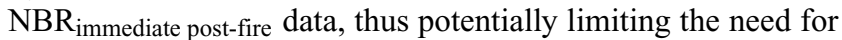
using $\mathrm{NBR}_{\text {pre }}$ to predict post-fire effects. These results concur with prior studies that relate both NBR and dNBR with CBI in forest and woodland environments (Epting et al. 2005) and are further supported by the correlation between the $\mathrm{dNBR}_{\text {immediate }}$ data and each of $\mathrm{NBR}_{\text {pre }}(r=0.93)$ and $\mathrm{NBR}_{\text {immediate }}(r=0.34)$ data. 
Table 6. Pearson correlation coefficient ( $r$ ) and Signal to Noise Ratio (SNR) analysis for bands 4 and 7

\begin{tabular}{|c|c|c|c|c|}
\hline & Variable 1 & Variable 2 & $r$ & Significance \\
\hline Prefire and immediate post-fire & Band 4 difference & Band 7 difference & -0.52 & 0.00 \\
\hline Prefire and 1 year post-fire & Band 4 difference & Band 7 difference & -0.33 & 0.01 \\
\hline SNR calculations using pre- and immediate post-fire imagery & & 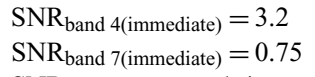 & & \\
\hline SNR calculations using pre and 1-year post-fire imagery & & $\begin{array}{l}\mathrm{SNR}_{\text {band } 4(1-\text { year })}=1.4 \\
\mathrm{SNR}_{\text {band } 7(1 \text {-year })}=0.47\end{array}$ & & \\
\hline
\end{tabular}

Immediate dNBR was a reasonable predictor of \% live trees $\left(\mathrm{r}^{2}=0.53\right), \%$ bole scorch $\left(\mathrm{r}^{2}=0.50\right)$ and weight of organic litter $\left(\mathrm{r}^{2}=0.59\right)$. Although 1-year post-fire dNBR outperformed immediate post-fire dNBR for most of the post-fire effects, the immediate measure did produce a marginally improved prediction, in terms of the coefficient of determination, of the depth of the 1-year post-fire litter. Again, these general results of higher coefficient of determination in using the 1 -year post-fire dNBR are as we expected, as this index incorporates data that are effectively coincident with the 1-year post-fire field measures. Furthermore, in a comparison with the preliminary data presented in Smith et al. (2007b), we did observe that removal of the 14 aspen plots from the regressions considerably improved the $r^{2}$ values and reduced the variability in the results. These results confirm our premise that coniferous cover types should be separately evaluated from deciduous cover types. For instance, the example of char fraction $v$. litter organic weight improved from $\mathrm{r}^{2}=0.55$ (s.e. $\left.=4.78\right)\left(\right.$ Smith et al. 2007b) to $\mathrm{r}^{2}=0.71$ $($ s.e. $=3.99)$ (present study). Similar improvement was observed using immediate dNBR data (Smith et al. 2007b).

\section{Discussion}

\section{Remote prediction of post-fire effects}

To predict implies to 'forecast a situation that is yet to occur'. Therefore, it is not appropriate to predict field measures of postfire effects with 1-year post-fire dNBR, as this is effectively measured concurrently with the 1-year post-fire field measures. Thus, the regressions herein were presented solely for the purpose of determining the 'potential inference ability' of the 1-year post-fire dNBR, not to forecast conditions 2, 5 or 10 years after fire (Table 4). Timely prediction of field-based ecological indicators of 1-year post-fire effects must instead be achieved through the use of methods applied either during or immediately following the fire event, as it is not practical to wait a year before making a 1-year post-fire prediction.

These results demonstrate that immediate dNBR was a poorer indicator of 1-year post-fire ecological effects than char cover fraction. Furthermore, immediate dNBR was in many cases a poorer indicator of 1 -year post-fire ecological effects. The ability of immediate dNBR to reasonably predict 1 -year post-fire $\%$ live crown is because the index is sensitive to the quantity of green and senesced vegetation (highlighted by Landsat band 4 values), and to a lesser extent, the quantity (and moisture content) of exposed soil or char cover (highlighted by Landsat band 7 values) present within the immediate post-fire pixel (Eva and Lambin 1998a , 1998b; Stroppiana et al. 2002; Smith et al. 2005; Key 2006; Lentile et al. 2006b). In instances where either the canopy component is relatively untouched or completely consumed (e.g. in a stand-replacing fire), the 1-year post-fire canopy conditions may still represent the same relative amount of green vegetation. In contrast, the understorey immediately following the fire will be dominated by char and mineral ash, which 1 year later will have been removed by wind and water or occluded by vegetation regrowth or scorched needlecast (Smith and Hudak 2005). As such, the contribution of band 7 to the 1 -year post-fire dNBR might simply be adding noise to the predictions of the subcanopy fire effects.

The majority of spectral indices are designed to highlight complementary changes in two or more bands. For NBR-based indices, we expect a lowering of reflectance in band 4 between the pre- and post-fire dates to correspond to a complementary increase in the value of band 7. Therefore, we would expect a significant correlation between these band differences: i.e. (b4 $\left.4_{\text {post }}-\mathrm{b} 4_{\text {pre }}\right)$ and $\left(\mathrm{b} 7_{\text {post }}-\mathrm{b} 7_{\text {pre }}\right)$. To test this assumption, correlations between the differences in band value pairs were calculated and are presented in Table 6 . Although the correlations of both band 4 and band 7 differences were both significant at the $95 \%$ confidence interval, the correlation between the band 4 difference and the band 7 difference was noticeably lower when using the 1 -year post-fire image value.

We further calculated a measure of the signal to noise ratio (SNR) for each of the band 4 and band 7 difference pairs (Table 6). This measure was determined by calculating both the mean and standard deviations of the band 4 and band 7 values of all the 66 plots for each image. In a similar manner to the SNR-based M-statistic (Pereira 1999), SNR was calculated by:

$$
S N R_{\text {band }(\mathrm{int})}=\frac{\left|\mu_{f}-\mu_{i}\right|}{\sigma_{f}+\sigma_{i}}
$$

where band(int) denotes the temporal interval between the prefire condition and either the immediate or 1-year post values for the band of interest (in this case band 4 or 7); $\mu$ and $\sigma$ denote the mean and standard deviations of all the 66 fire-affected plots for the band of interest; and $i$ denotes the prefire data, and $f$ denotes the post-fire image values.

The $\mathrm{SNR}_{\text {band }} 4$ (immediate) $=3.2$, whereas the $\mathrm{SNR}_{\text {band }}$ 4(1-year) $=$ 1.4. The SNR for band 7 changed in a similar manner, with $\mathrm{SNR}_{\text {band } 7 \text { (immediate) }}=0.75$ and $\mathrm{SNR}_{\text {band } 7 \text { (1-year) }}=0.47$. It is clear that both the band 4 and band 7 values have notable decreases in their SNR when using the 1-year post-fire image values compared with the usage of the immediate post-fire imagery. These results lend support to the proposition that the application of 1-year post-fire band values may not be optimal for assessing post-fire effects. 


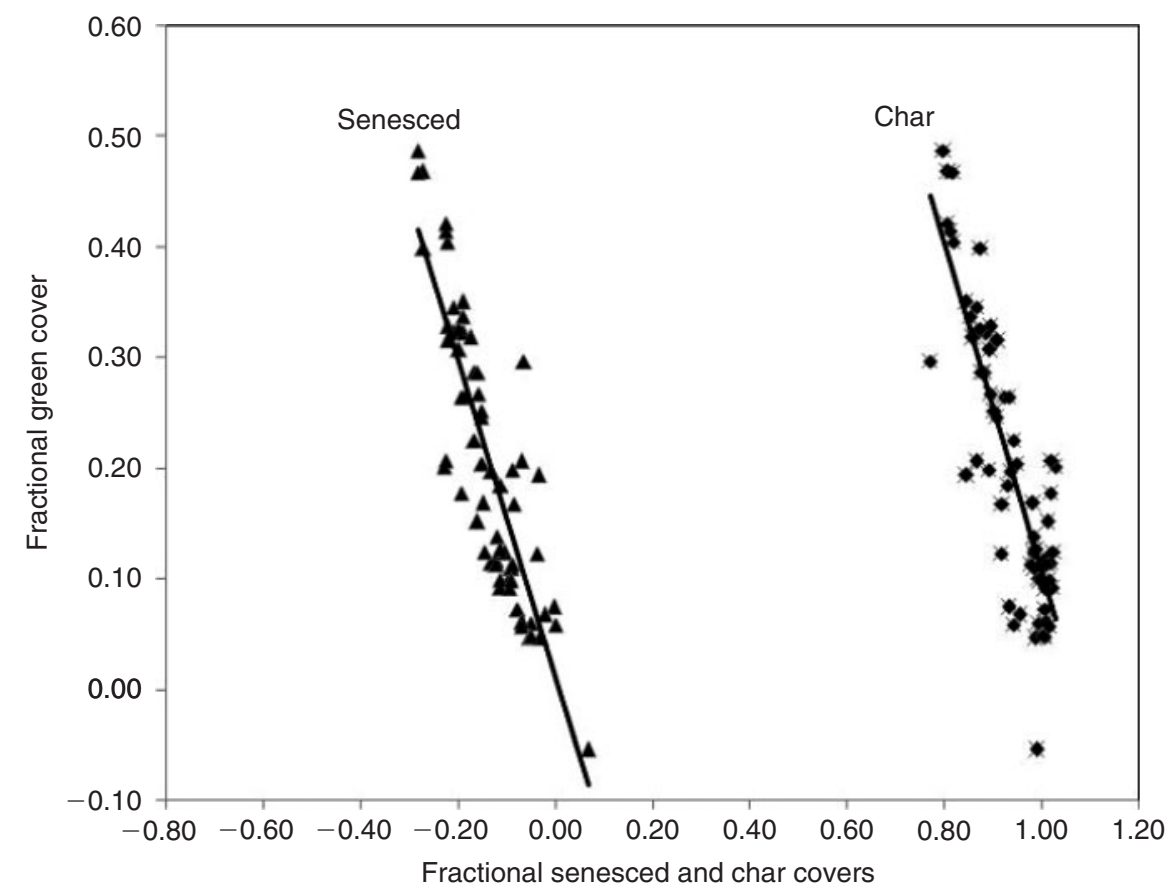

Fig. 4. Correlation of fractional cover measures where dark lines depict the main linear trend. Scatter plot of fractional green and senesced vegetation cover $(r=-0.86)$ and scatter plot of fractional char cover with green vegetation $(r=-0.85)$.

These effects would be less pronounced where canopy closure remains high (unburned or low degree of fire effects) or in stand-replacing fires where the understorey vegetation could be replaced by bare soil. The unexpected ability of the immediate NBR and dNBR to predict the 1-year post-fire measure of organic litter weight could be an indirect effect of the combined impact of scorched canopies with extensive surface fires. In such fires, we would expect the surface material to be consumed and scorched needles to fall as new litter for the 1-year post-fire measurement, as highlighted in several studies (Robichaud and Brown 2000; Pannkuk and Robichaud 2003; Robichaud 2004). In contrast, low-severity fires and stand-replacing fires would result in high and low organic litter weights respectively.

Measures of both the immediate post-fire char and green vegetation fractions are good predictors of several 1-year post-fire canopy and several subcanopy measures. Most notable, several of these 1-year post-fire measures appear to be potential surrogates of fire intensity. Specifically, $\%$ bole scorch can be considered a proxy for flame length, while scorch to $1 \mathrm{~m}$ and organic litter weight might each relate to rate of spread, and average bark thickness might similarly relate to fire duration. Therefore, these fractional measures have the potential to inform managers regarding tree mortality (via canopy condition and average bark thickness) and may provide viable proxies of fire intensity to Burned Area Emergency Response (BAER) teams tasked with deciding where post-fire mitigation efforts are needed.

Of the fractions considered, char fraction was marginally better over green fraction for predicting several metrics of fire severity 1 year after fire. This leads to the question, 'Are these two fractions providing redundant or complimentary information?'
This is an important distinction, as the degree to which the information is unique to each fraction would indicate whether or not a composite metric of the two fractions could be used to produce an improved burn severity remote sensing method. To answer this question, we first assessed the correlation between the component fractions (Fig. 4), and second assessed the variability that each fraction term accounted for in the predictions of each of the 1-year post-fire field measures (Table 5).

The correlations of the green fraction with both the char and the senesced vegetation fractions were significant and high $(r=\sim 0.85$ ); however, the char and brown fractions were only poorly correlated $(r=0.46)$ (Fig. 4$)$. Although the fractions are relative, the brown (senesced) component produced 'negative' fractions, suggesting that this term is not optimal and perhaps is accounting for the lack of a specific soil endmember. However, without detailed soil maps and spectral reflectance curves for each soil type, it would be difficult to replace the brown endmember with representative soil endmembers.

In multiple linear regressions of the component fractions against the organic litter weight, only the char fraction and the combination of the char with the green fraction produced significant results at the $95 \%$ confidence level. In the example of the organic litter weight measure, the char fraction alone accounted for $71 \%$ of the variance, with the addition of the green fraction only accounting for an additional $2 \%$ of the variability. In each of the two cases of bole scorch and percentage live tree, addition of the green fraction within the regression was not significant and only accounted for an additional $2 \%$ variance explained over the char fraction. These results limit the likelihood that a combination index using both the char and green vegetation fractions 
Table 7. Relation between \% cover measures of burn severity and carbon $(\mathrm{C})$ and water $\left(\mathrm{H}_{2} \mathrm{O}\right)$ cycles ET denotes evapotranspiration

\begin{tabular}{lll}
\hline Ecological metrics & Fire-effects reference(s) & Linkages to $\mathrm{C}$ and $\mathrm{H}_{2} \mathrm{O}$ cycles \\
\hline Tree survival or mortality & Miller and Yool (2002) & C accumulation, ET rates \\
Bare soil & Goforth et al. al. (2003); Trumbore (2006) & \\
Reddened soil & Doerr and Cerda (2005) & Plant establishment, soil respiration rates \\
Exposed litter & Lewis et al. $(2006)$ & Infiltration, water repellency and erosion \\
& Crockford and Richardson (2000) & Plant establishment, water repellency \\
White ash & Smith et al. $(2005)$ & Surface evaporation \\
Coarse woody debris & Smith and Hudak (2005) & C volatilization, water repellency \\
\hline
\end{tabular}

would provide significantly improved predictions over just the char fraction alone.

\section{Management and science implications}

Immediate post-fire assessments, particularly those that utilize only immediate post-fire dNBR techniques, can be misleading. The post-fire environment will change greatly within 1 year, some aspects of which may be predictable whereas others may be related to local and regional climate. Char fractional cover may be a viable alternative to dNBR to predict longer-term post-fire ecological effects, especially when the prediction is needed in a timely manner. For instance, BAER teams must make post-fire rehabilitation treatment recommendations within 7 days following fire containment. Second, post-fire response generally is more rapid in less severely burned areas. However, commonly applied dNBR techniques provide very little information about the effects of fire on the forest floor and soil. As such, char fraction is particularly useful in fire regimes where some, but not all, of the overstorey tree and shrub canopy is consumed. The mosaic of relatively small patches of severely burned forests interspersed within less severely burned forests, a common signature of surface fires and mixed-severity fire regimes, exerts a strong influence on post-fire landscape heterogeneity and rates of response. In some extensive areas of high-severity fire, postfire vegetation dynamics may not follow the same trajectory as less severely burned areas, and a cover type conversion from forests to shrubs or meadows may occur.

From a management perspective, streamlined assessment of fire effects on overstorey, understorey and forest floor environments can be used to predict areas likely to develop vegetation structure different from prefire conditions, and will facilitate post-fire monitoring and mitigation (Lentile et al. 2007b). Identification of desirable attributes of fire behavior and positive post-fire effects may improve restoration strategies. For example, recognition of initial fire effects likely to result in tree death may facilitate selection of which trees to salvage-harvest or leave as potential seed sources. In some burned areas, reforestation or seeding are probably unnecessary and could interfere with natural successional dynamics. Furthermore, severely burned areas with post-fire vegetation regrowth may indicate areas that require immediate attention for erosion control or are highly vulnerable to displacement of native flora by invasive species. If a cover type conversion from ponderosa pine to shrub-dominated communities is desirable for wildlife habitat diversity, then large patches of high severity may lend themselves to this objective. Longer-interval, large fire events, such as the Jasper Fire, may be critical in maintaining landscape heterogeneity and diversity. Openings in a previously dense, closed-canopy forest may represent a desirable departure from prefire conditions and a return of some attributes of historical landscape function. Rapid landscape characterization that can be mechanistically related to ground measures of post-fire ecosystem condition may provide much needed management guidance and decision support following large fire events.

The post-fire effects measured in the field typically reflect fine-scale processes, but also impact coarse spatial (watershed to regional) and temporal (decadal) scales. For such measures to be applicable in describing ecosystem recovery and condition across a range of scales and ecosystems, they should physically relate to pools and fluxes of biophysical variables (e.g. the carbon and water cycles). Although the mechanistic relations between fire effects and the carbon and water cycles are not currently well defined, the results of the present study support the argument that cover fractions are potentially versatile measures of postfire ecological impact that also influence the terrestrial carbon and water cycles (Table 7).

\section{Conclusions}

The previous study of Smith et al. (2007b) reported for the Jasper Fire that the modeled estimate of the \% char was a slightly improved predictor over immediate dNBR of two 1-year postfire field measures, namely the \% live tree and the organic litter weight. However, given the conflicting findings of Hudak et al. (2007b) with respect to fractional green cover estimates and the recognition that the initial study incorrectly analyzed both ponderosa pine and aspen stands together, further analysis of this dataset was warranted. Specifically, assessment to investigate whether the char and other modeled estimates of the immediate post-fire fractional covers (green and senesced vegetation) could also predict an expanded variety of both canopy (four) and subcanopy (nine) post-fire effects. These field measures were selected based on whether they could provide a reasonable bridge between the fire intensity and the fractional cover estimates. An investigation was also included of whether a combination of different fractional cover estimates could act as improved predictor of the post-fire effects, or whether the different fractional cover estimates account for the same variability. For the sake of completeness with contemporary remote sensing post-fire 
effects research, the present study further investigated whether the dNBR indices, both immediate and 1-year post-fire, were improved predictors when compared with the fractional cover estimates.

The results demonstrated that although the char cover fraction either equaled or outperformed all other immediate measures in predicting 1-year post-fire effects, the green fractional cover was a reasonable predictor for several of the post-fire measures. Although the char and green cover fractions provided improved predictions of the 1-year post-fire effects over the immediate post-fire NBR and dNBR measures, predictions incorporating both the char and green fractional covers only accounted for $\sim 2 \%$ more variability than that achieved using the char fraction cover alone. This result combined with the ineffectiveness of the brown fractional cover highlight the limited utility for a combination approach based on several different cover metrics. The comparison of immediate post-fire NBR with dNBR showed that the inclusion of the prefire NBR data did not provide any notable improvement in the predictions of the 1-year post-fire measures. Therefore, perhaps future studies may not need to consider prefire imagery in order to predict several 1-year post-fire canopy and subcanopy effects.

Although in the present study, application of the char and green fractional covers to predict 1-year post-fire effects were an improvement over NBR and dNBR, we do not suggest that this approach or that of any other spectral index currently existing will be a panacea for evaluating burn severity in all fire-affected environments (e.g. savannah grasslands, temperate forests, boreal forests, woodlands, chaparral, scrublands). In contrast, it is more likely that a suite of methods will need to be identified, where each separate method in this suite will be optimal for predicting $>1$ year post-fire effects in a single environment. To enable robust national and global burn severity products, further research is warranted to identify and evaluate these methods.

The principal limitation of the current study is that it only represents information from a single wildfire at one point in time. Research is clearly warranted to repeat this analysis on data collected from fires 5, 10 or even 20 years post-fire, to evaluate the potential for inferences from immediate post-fire remote sensing data to predict long-term ecological responses to fire, such as succession processes and carbon accumulation. Future research should also evaluate how changes in surface cover fractions relate to both these differenced indices and to changes in remotely sensed fractional cover. This could be achieved via the analysis of prescribed fires, where it is possible to collect information on the prefire fractional cover of flammable and non-flammable materials.

\section{Acknowledgements}

The present fieldwork component of the current study was funded by the Black Hills National Forest through In-Service Agreement No. 0203-01007, Monitoring Fire Effects and Vegetation Recovery on the Jasper Fire, Black Hills National Forest, South Dakota to Rocky Mountain Research Station and Colorado State University. The subsequent research was supported in part by funds provided by the Rocky Mountain Research Station, Forest Service, US Department of Agriculture (03-JV-11222065-279) and the USDA/USDI Joint Fire Science Program (Projects 03-2-1-02 and 05-4-107). Partial support for Smith was obtained from the NSF Idaho EPSCoR Program and by the National Science Foundation under award number
EPS-0814387. We thank the Associate Editor, Mark Cochrane and the other anonymous reviewer whose comments greatly improved the present manuscript.

\section{References}

Atkinson PM, Cutler MEJ, Lewis H (1997) Mapping sub-pixel proportional land cover with AVHRR imagery. International Journal of Remote Sensing 18, 917-935. doi:10.1080/014311697218836

Bobbe T, Finco MV, Quayle B, Lannom K, Sohlberg R, Parsons A (2003) Field measurements for the training and validation of burn severity maps from spaceborne, remotely sensed imagery. USDI Joint Fire Science Program, Final Project Report JFSP RFP 2001-2. (Boise, ID)

Borel CC, Gerstl SAW (1994) Non-linear spectral mixing models for vegetative and soil surfaces. Remote Sensing of Environment 47, 403-416. doi:10.1016/0034-4257(94)90107-4

Brewer CK, Winne JC, Redmond RL, Opitz DW, Magrich MV (2005) Classifying and mapping wildfire severity: a comparison of methods. Photogrammetric Engineering and Remote Sensing 71(11), 1311-1320.

Brown JK, Smith JK (Eds) (2000) Wildland fire in ecosystems: effects of fire on flora. USDA Forest Service, Rocky Mountain Research Station, General Technical Report RMRS-GTR-42. (Ogden, UT)

Chen X, Vierling L, Rowell E, DeFelice T (2004) Using Lidar and effective LAI to evaluate IKONOS and Landsat 7 ETM+ vegetation estimates in a ponderosa pine forest. Remote Sensing of Environment 91, 14-26. doi:10.1016/J.RSE.2003.11.003

Clark RN, Lucey PG (1984) Spectral properties of ice-particulate mixtures and implications for remote sensing 1. Intimate mixtures. Journal of Geophysical Research 89(B7), 6341-6348. doi:10.1029/JB089IB07P06341

Cochrane MA, Souza CM (1998) Linear mixture model classification of burned forests in the Eastern Amazon. International Journal of Remote Sensing 19(17), 3433-3440. doi:10.1080/014311698214109

Cocke AE, Fulé PZ, Crouse JE (2005) Comparison of burn severity assessments using differenced Normalized Burn Ratio and ground data. International Journal of Wildland Fire 14(2), 189-198. doi:10.1071/ WF04010

Cracknell AP (1998) Synergy in remote sensing - what's in a pixel? International Journal of Remote Sensing 19(11), 2025-2047. doi:10.1080/014311698214848

Crockford RH, Richardson DP (2000) Partitioning of rainfall into throughfall, stemflow and interception: effect of forest type, ground cover and climate. Hydrological Processes 14, 2903-2920. doi:10.1002/10991085(200011/12)14:16/17<2903::AID-HYP126>3.0.CO;2-6

De Santis A, Chuvieco E (2007) Burn severity estimation from remotely sensed data: performance of simulation versus empirical models. Remote Sensing of Environment 108, 422-435. doi:10.1016/J.RSE.2006.11.022

Doerr SH, Cerda A (2005) Fire effects on soil system functioning: new insights and future challenges. International Journal of Wildland Fire 14, 339-342. doi:10.1071/WF05094

Dozier J, Strahler AH (1983) Ground investigations in support of remote sensing. In 'Manual of Remote Sensing'. (Eds RN Colwell, DS Simonett, GA Thorley) pp. 959-986. (American Society of Photogrammetry: Falls Church, VA)

Drake NA, Mackin S, Settle JJ (1999) Mapping vegetation, soils, and geology in semiarid shrublands using spectral matching and mixture modeling of SWIR AVIRIS imagery. Remote Sensing of Environment 68, 12-25. doi:10.1016/S0034-4257(98)00097-2

Drake NA, White K (1991) Linear mixture modelling of Landsat Thematic Mapper data for mapping the distribution and abundance of gypsum in the Tunisian Southern Atlas. In 'Spatial Data 2000: Proceedings of a Joint Conference of the Photogrammetric Society, the Remote Sensing Society, the American Society for Photogrammetry and Remote Sensing', Christ Church, Oxford. (Ed. I Dowman) pp. 168-177. (Remote Sensing Society: Nottingham, UK) 
Elvidge CD (1990) Visible and near-infrared reflectance characteristics of dry plant materials. International Journal of Remote Sensing 11, 1775-1795. doi:10.1080/01431169008955129

Epting J, Verbyla D, Sorbel B (2005) Evaluation of remotely sensed indices for assessing burn severity in interior Alaska using Landsat TM and ETM+. Remote Sensing of Environment 96(3-4), 328-339. doi:10.1016/J.RSE.2005.03.002

Eva H, Lambin EF (1998a) Burnt area mapping in Central Africa using ATSR data. International Journal of Remote Sensing 19(18), 3473-3497. doi:10.1080/014311698213768

Eva H, Lambin EF (1998b) Remote sensing of biomass burning in tropical regions: sampling issues and multisensor approach. Remote Sensing of Environment 64, 292-315. doi:10.1016/S0034-4257(98)00006-6

Foody GM, Lucas RM, Curran PJ, Honzak M (1997) Non-linear mixture modelling without end-members using an artificial neural network International Journal of Remote Sensing 18(4), 937-953. doi:10.1080/ 014311697218845

Foody GM (2000) Estimation of sub-pixel land cover composition in the presence of untrained classes. Computers \& Geosciences 26(4), 469-478. doi:10.1016/S0098-3004(99)00125-9

Goforth BR, Graham RC, Hubbert KR, Zanner CW, Minnich RA (2005) Spatial distribution and properties of ash and thermally altered soils after high-severity forest fire, southern California. International Journal of Wildland Fire 14, 343-354. doi:10.1071/WF05038

Holden Z, Smith AMS, Morgan P, Rollins MG, Gessler PE (2005) Evaluation of novel thermally enhanced spectral indices for mapping fire perimeters and comparisons with fire atlas data. International Journal of Remote Sensing 26(21), 4801-4808. doi:10.1080/01431160500239008

Hudak AT, Morgan P, Bobbitt M, Lentile L (2007a) Characterizing standreplacing harvest and fire disturbance patches in a forested landscape: a case study from Cooney Ridge, Montana. In 'Understanding Forest Disturbance and Spatial Patterns: Remote Sensing and GIS Approaches'. (Eds MA Wulder, SE Franklin) pp. 209-231. (Taylor \& Francis: London)

Hudak AT, Morgan P, Bobbitt MJ, Smith AMS, Lewis SA, Lentile LB, Robichaud PR, Clark JT, McKinley RA (2007b) The relationship of multispectral satellite imagery to immediate fire effects. Fire Ecology 3, 64-90.

Huete AR, Escadafal R (1991) Assessment of biophysical soil properties through spectral decomposition techniques. Remote Sensing of Environment 35, 149-159. doi:10.1016/0034-4257(91)90008-T

Key CH (2006) Ecological and sampling constraints on defining landscape fire severity. Fire Ecology 2, 2178-203.

Key CH, Benson NC (2006) Landscape assessment: ground measure of severity, the Composite Burn Index; and remote sensing of severity, the Normalized Burn Ratio. In 'FIREMON: Fire Effects Monitoring and Inventory System'. (Eds DC Lutes, RE Keane, JF Caratti, CH Key, NC Benson, S Sutherland, LJ Gangi) USDA Forest Service, Rocky Mountain Research Station General Technical Report RMRS-GTR-164-CD, pp. LA1-51. (Ogden, UT)

Keyser TL (2007) Changes in forest structure, community composition, and development in ponderosa pine forests following a mixed-severity wildfire in the Black Hills, SD, USA. PhD thesis, Colorado State University.

Keyser TL, Smith FW, Lentile LB, Shepperd WD (2006) Modeling post-fire mortality of ponderosa pine following a mixed-severity wildfire in the Black Hills: the role of tree morphology and direct fire effects. Forest Science 52, 530-539.

Keyser TL, Smith FW, Shepperd WD (2005) Trembling aspen response to a mixed-severity wildfire in the Black Hills, South Dakota, USA. Canadian Journal of Forest Research 35, 2679-2684. doi:10.1139/X05-180

Landmann T (2003) Characterizing sub-pixel Landsat ETM+ fire severity on experimental fires in the Kruger National Park, South Africa. South African Journal of Science 99, 357-360.

Lawrence RL, Ripple WJ (1998) Comparisons among vegetation indices and bandwise regression in a highly disturbed, heterogeneous landscape:
Mount St Helens, Washington. Remote Sensing of Environment 64 91-102. doi:10.1016/S0034-4257(97)00171-5

Lentile LB (2004) Causal factors and consequences of mixed-severity fire in Black Hills ponderosa pine forests. PhD Thesis, Colorado State University.

Lentile LB, Smith FW, Shepperd WD (2005) Patch structure, fire-scar formation and tree regeneration in a large mixed-severity fire in the South Dakota Black Hills, USA. Canadian Journal of Forest Research 35, 2875-2885. doi:10.1139/X05-205

Lentile LB, Smith FW, Shepperd WD (2006a) The influence of topography and forest structure on patterns of mixed-severity fire in the South Dakota Black Hills. International Journal of Wildland Fire 15(4), 557-566. doi:10.1071/WF05096

Lentile LB, Holden ZA, Smith AMS, Falkowski MJ, Hudak AT, Morgan P, Lewis SA, Gessler PE, Benson NC (2006b) Remote sensing techniques to assess active fire and post-fire effects. International Journal of Wildland Fire 15, 319-345. doi:10.1071/WF05097

Lentile LB, Morgan P, Hardy C, Hudak A, Means R, Ottmar RD, Robichaud PR, Sutherland EK, et al. (2007a) Value and challenges of conducting rapid response on wildland fires. USDA Forest Service, Rocky Mountain Research Station, General Technical Report RMRS-GTR-193. (Fort Collins, CO)

Lentile LB, Morgan P, Hudak AT, Bobbitt MJ, Lewis SA, Smith AMS, Robichaud PR (2007b) Post-fire burn severity and vegetation response following eight large wildfires across the western US. Fire Ecology $\mathbf{3}$, 91-108.

Lewis SA, Wu JQ, Robichaud PR (2006) Assessing burn severity and comparing soil water repellency, Hayman Fire, Colorado. Hydrological Processes 20, 1-16. doi:10.1002/HYP.5880

Lewis SA, Lentile LB, Hudak AT, Robichaud PR, Morgan P, Bobbitt MJ (2007) Mapping ground cover using hyperspectral remote sensing after the 2003 Simi and Old wildfires in Southern California. Fire Ecology 3, $109-128$.

Litton CM, Ryan MG, Knight DH, Stahl PD (2003) Soil-surface carbon dioxide efflux and microbial biomass in relation to tree density 12 years after a stand-replacing fire in a lodgepole pine ecosystem. Global Change Biology 9, 680-696. doi:10.1046/J.1365-2486.2003. 00626.X

López-García MJ, Caselles V (1991) Mapping burns and natural reforestation using Thematic Mapper data. Geocarto International 6, 31-37. doi:10.1080/10106049109354290

Miller JD, Thode AE (2007) Quantifying burn severity in a heterogeneous landscape with a relative version of the delta Normalized Burn Ratio (dNBR). Remote Sensing of Environment 109, 66-80. doi:10.1016/ J.RSE.2006.12.006

Miller JD, Yool SR (2002) Mapping forest post-fire canopy consumption in several overstory types using multi-temporal Landsat TM and ETM data. Remote Sensing of Environment 82, 481-496. doi:10.1016/S00344257(02)00071-8

Morgan P, Hardy CC, Swetnam T, Rollins MG, Long LG (2001) Mapping fire regimes across time and space: understanding coarse and finescale fire patterns. International Journal of Wildland Fire 10, 329-342. doi:10.1071/WF01032

Nagler PL, Daughtry CST, Goward SN (2000) Plant litter and soil reflectance. Remote Sensing of Environment 71, 207-215. doi:10.1016/ S0034-4257(99)00082-6

Odion DC, Hanson CT (2006) Fire severity in conifer forests of the Sierra Nevada, California. Ecosystems 9, 1177-1189. doi:10.1007/S10021003-0134-Z

Odion DC, Hanson CT (2007) Fire severity in the Sierra Nevada revisited: conclusions robust to further analysis. Ecosystems 11, 12-15. doi:10.1007/S10021-007-9113-0

Pannkuk CK, Robichaud PR (2003) Effectiveness of needle cast at reducing erosion after forest fires. Water Resources Research 39, 1333-1343. doi:10.1029/2003WR002318 
Patterson MW, Yool SR (1998) Mapping fire-induced vegetation mortality using Landsat Thematic Mapper data: a comparison of linear transformation techniques. Remote Sensing of Environment 65, 132-142. doi:10.1016/S0034-4257(98)00018-2

Pereira JMC (1999) A comparative evaluation of NOAA/AVHRR vegetation indexes for burned surface detection and mapping. IEEE Transactions on Geoscience and Remote Sensing 37(1), 217-226. doi:10.1109/36. 739156

Qin W, Gerstl SAW (2000) 3-D scene modelling of semi-arid vegetation cover and its radiation regime. Remote Sensing of Environment 74, 145-162. doi:10.1016/S0034-4257(00)00129-2

Robichaud PR (2004) Post-fire rehabilitation: are we learning what works? Southwest Hydrology 3, 20-21.

Robichaud PR, Brown RE (2000) What happened after the smoke cleared: onsite erosion rates after a wildfire in Eastern Oregon. In 'Proceedings of the Wildland Hydrology Conference', 20 June-2 July 1999, Bozeman, MT. (Eds DS Olsen, JP Potyondy) pp. 419-426. (American Water Resource Association: Herndon, VA)

Robichaud PR, Lewis SA, Laes DYM, Hudak AT, Kokaly RF, Zamudio JA (2007) Post-fire soil burn severity mapping with hyperspectral image unmixing. Remote Sensing of Environment 108, 467-480. doi:10.1016/ J.RSE.2006.11.027

Roy DP, Boschetti L, Trigg SN (2006) Remote sensing of fire severity: assessing the performance of the normalized burn ratio. IEEE Geoscience and Remote Sensing Letters 3(1), 112-116. doi:10.1109/LGRS.2005.858485

Ryan KC, Noste NV (1985) Evaluating prescribed fires. In 'Proceedings of the Symposium and Workshop on Wilderness Fire', 15-18 November 1983, Missoula, MT. (Eds JE Lotan, BM Kilgore, WC Fischer, RW Mutch) USDA Forest Service, Intermountain Forest and Range Experiment Station, General Technical Report INT-GTR-182, pp. 230-238. (Ogden, UT)

Safford HD, Miller JD, Schmidt D, Roath B, Parsons A (2007) BAER soil burn severity maps do not measure fire effects to vegetation: a comment on Odion and Hanson (2006). Ecosystems 11, 1-11. doi:10.1007/ S10021-007-9094-Z

Settle JJ, Drake NA (1993) Linear mixing and the estimation of ground cover proportions. International Journal of Remote Sensing 14(6), 1159-1177. doi:10.1080/01431169308904402

Shepperd WD, Battaglia MA (2002) Ecology, silviculture, and management of Black Hills ponderosa pine. USDA Forest Service, Rocky Mountain Research Station, General Technical Report RMRS-97. (Fort Collins, CO)

Smith AMS, Hudak AT (2005) Estimating combustion of large downed woody debris from residual white ash. International Journal of Wildland Fire 14, 245-248. doi:10.1071/WF05011

Smith AMS, Wooster MJ, Drake NA, Dipotso FM, Falkowski MJ, Hudak AT (2005) Testing the potential of multi-spectral remote sensing for retrospectively estimating fire severity in African savannahs environments. Remote Sensing of Environment 97(1), 92-115. doi:10.1016/J.RSE.2005.04.014

Smith AMS, Drake NA, Wooster MJ, Hudak AT, Holden ZA, Gibbons CJ (2007a) Production of Landsat ETM+ reference imagery of burned areas within Southern African savannahs: comparison of methods and application to MODIS. International Journal of Remote Sensing 28, 2753-2775. doi:10.1080/01431160600954704

Smith AMS, Lentile LB, Hudak AT, Morgan P (2007b) Evaluation of linear spectral unmixing and $\triangle \mathrm{NBR}$ for predicting post-fire recovery in a N. American ponderosa pine forest. International Journal of Remote Sensing 28, 5159-5166. doi:10.1080/01431160701395161

Stroppiana D, Pinnock S, Pereira JMC, Gregoire JM (2002) Radiometric analysis of SPOT-VEGETATION images for burnt area detection in Northern Australia. Remote Sensing of Environment 82, 21-37. doi:10.1016/S0034-4257(02)00021-4

Theseira MA, Thomas G, Sannier CAD (2002) An evaluation of spectral mixture modeling applied to a semi-arid environment. International Journal of Remote Sensing 23, 687-700. doi:10.1080/01431160010019652

Theseira MA, Thomas G, Taylor JC, Gemmell F, Varjo J (2003) Sensitivity of mixture modelling to end-member selection. International Journal of Remote Sensing 24(7), 1559-1575. doi:10.1080/01431160210146631

Townshend JGR, Huang C, Kalluri SNV, Defries RS, Liang D (2000) Beware of per-pixel characterization of land cover. International Journal of Remote Sensing 21(4), 839-843. doi:10.1080/014311600210641

Trumbore S (2006) Carbon respired by terrestrial ecosystems - recent progress and challenges. Global Change Biology 12(2), 141-153. doi:10.1111/J.1365-2486.2006.01067.X

Vafeidis AT, Drake NA (2005) A two-step method for estimating the extent of burnt areas with the use of coarse-resolution data. International Journal of Remote Sensing 26(11), 2441-2459. doi:10.1080/ 01431160500034102

Verstraete MM, Pinty B (1996) Designing optimal spectral indices for remote sensing applications. IEEE Transactions on Geoscience and Remote Sensing 34(5), 1254-1265. doi:10.1109/36.536541

van Wagtendonk JW, Root RR, Key CH (2004) Comparison of AVIRIS and Landsat ETM+ detection capabilities for burn severity. Remote Sensing of Environment 92, 397-408. doi:10.1016/J.RSE.2003.12.015

Wessman CA, Bateson CA, Benning TL (1997) Detecting fire and grazing patterns in tallgrass prairie using spectral mixture analysis. Ecological Applications 7(2), 493-511. doi:10.1890/1051-0761(1997)007[0493: DFAGPI]2.0.CO;2

Wimberly MC, Reilly MJ (2007) Assessment of fire severity and species diversity in the southern Appalachians using Landsat TM and ETM+ imagery. Remote Sensing of Environment 108, 189-197. doi:10.1016/J.RSE.2006.03.019

Manuscript received 12 July 2007, accepted 21 August 2008 